\section{THE CHEMICAL RESEARCH LABORATORY, TEDDINGTON}

$\mathrm{T}$

HE report of the Chemistry Research Board for 1948 , issued with the report of the Director of the Chemical Research Laboratory under the title "Chemistry Research 1948"*, like the report for 1938-46, which appeared last year, refers to both the long-term and the short-term aspects of the work of the Laboratory. After considering an important paper from the Director on the functions and future policy of the Laboratory, the Board decided to recom. mend that the general functions of the Laboratory should be: $(a)$ to carry out objective fundamental chemical research including developmental work so far as this may be necessary to establish the industrial value of any discoveries which may be made; (b) to carry out appropriate chemical research on request and to provide technical advice to other sections of the Department of Scientific and Industrial Research, other government departments and British industry.

The Board thinks it appropriate that the work of a national research establishment should have this dual nature, but that a proper balance must be preserved between the two aspects. Mindful possibly of comments from the Select Committee on Estimates in regard to expenditure on research and develop. ment, the Board emphasizes that careful selection of topics in the programme of fundamental research is essential. Detailed consideration of the general policy which should determine the choice leads it to the opinion that long-range problems of chemistry or chemical technology, of a type which require attack by a skilled team over a long period, should be studied. The work should not duplicate that proceeding in British universities and industry, although duplication may not always be avoidable.

Five main themes are considered particularly appropriate for inclusion in the future programme of the Laboratory. First of these are researches leading to fundamental reference data of general value, such as precise data on the fundamental constants of pure chemical compounds. Second come new methods and techniques of chemistry in which it is desirable that an expert group should be maintained, particularly those which are so difficult or expensive as to be beyond the range of small research units. The Board recommended in 1944 that the Laboratory should pay particular attention to new techniques in its post-war programme, and subsequent developments have shown that this is one of the most useful fields in which the Laboratory can work. Next, the conservation of essential materials is recommended, with the objective of husbanding material resources, particularly key materials. Related to this is the utilization of indigenous raw materials, especially those of low grade, including wastes. The basic problems here are often technically difficult and demand long-term efforts for their solution. The main example of such work is to be found in that going forward at the Laboratory for the Ministry of Supply. Lastly, the investigation of potentially interesting new processes and materials is recommended.

The establishment of a Pure Metals Committee to stimulate interest in and co-ordinate the preparation

- Department of Scientific and Industrial Research. Report of the Chemistry Research Board, with the Report of the Director of the Chemical Research Laboratory for the Year 1948. Pp. vi $+82+2$ plates. (London: H.M. Stationery Office, 1949.) 28. net. of pure metals for research and development, and of a High Polymers Committee, under the chairmanship of Prof. H. W. Melville, in July 1948, are in line with these main themes. The Board, however, also undertook during the year a special review of current activities to ensure that the resources of the Laboratory were being applied in the most effective manner, having regard to the present national situation. It is agreed that it is necessary at present to ensure that every effort is made to apply scientific knowledge effectively, and that all possible help is given in the solution of current practical problems of importance in industry and government depart. ments; but anxiety is expressed lest the fundamental research of the Laboratory may suffer in consequence.

In consequence of this change of plan, advisory and liaison work has increased in all sections, while in the re-organisation of the organic chemistry research of the Laboratory, the Coal Tar Section, which was one of the first major sections, has ceased to exist. In the re-orientation a prominent place has been assigned to the accurate determination of physical and physico-chemical data for pure organic compounds, and the Laboratory is developing its contact with the Hydrocarbon Research Group of the Institute of Petroleum. Prominence has also been given to investigations on the insecticidal properties of compounds derived from coal tar bases, the evaluation and development of acenaphthylene polymers and co-polymers, and new analytical pro. cedures for certain coal-tar compounds. A programme of work has been initiated on the preparation of isotopically labelled organic compounds ; thus far the emphasis has been on the stable isotopes, and special procedures necessary for the manipulation and synthesis on the micro-scale of labelled compounds and simple intermediates containing carbon-13 have been evolved.

The Board refers particularly to the striking advances made at the Laboratory in the chromatographic separation of inorganic materials by a new technique involving the use of cellulose and other absorbing materials on one hand and of organic solvents containing additional reagents on the other, as well as to the concentration of effort by the High Polymers Section on problems relating to the ionexchange and allied properties of synthetic resins. Considerable progress has been made in correlating the ion-exchange behaviour of polymers with their structure, and in the separation of pyridine and piperidine by the displacement-development tech. nique on a cation exchange agent. Interesting results have been obtained from the study of the chemical reactivity of the chlorine atoms in polyvinyl chloride, particularly with ammonia and substituted ammonias. The discovery that, in the preparation of cold-setting resorcinol-formaldehyde adhesives, the technically pure resorcinol can be replaced by a crude resorcinol fraction from the low-temperature carbonization of coal provides a useful outlet for a virtual by-product.

Fuller details of these and other developments 'are given in the Director's own report. The Laboratory is now organised in four groups and an independent section, with an exploratory unit for investigations under the personal supervision of the Director. In the independent section, work carried out on polymers derived from bases other than hexamethylenediamine was being concluded; but the synthesis of longchain compounds received considerable attention, including a continuous conversion of caproic acid to 
$n$-decane by a modified Kolbe reaction, and decarboxylation studies on succinic anhydride and on unsaturated acids. In the Corrosion of Metals Group additional work has been carried out on the high-speed and low-speed rotor-technique under immersed conditions, while further studies of the relation between the electrical conductance and the area of breakdown of paint coatings on metal immersed in sea-water have shown that small areas of paint breakdown have a greater relative effect than large areas. Corrosion tests of about sixty low-alloy steels, using the intermittent spray apparatus, have been completed, and quantitative tests confirm that the depth of colour of the corrosion product and its adhesion to its steel basis are closely associated with the corrosion characteristics of the metal. Other work has been concerned with organic corrosion inhibitors such as sodium phthalate and sodium benzoate, both under immersed conditions and in wrapping materials. A temporary protective has been formulated based on rubber latex with sodium benzoate as inhibitor. The influence of surface pre-treatment and the composition and structure of oxide films on mild steel have also received attention, while the Microbiology Section has studied the culture and morphology of sulphatereducing bacteria and the inhibitory action of antibiotics and antiseptics towards such bacteria, and established that mild but not stainless steel is corroded in cultures of such bacteria, as well as that such bacteria are a supplementary factor in the internal corrosion of water mains, especially in clay soils.

The Inorganic Group has given further attention to the extraction of gallium and germanium from flue dust, to the lower valency states of gallium and to the preparation of pure vanadium pentoxide, as well as to general techniques for extraction, microanalysis and spectroscopic analysis. The Radiochemical Group continued to work on the same lines as in the previous year, including analytical methods for the determination of uranium, thorium and other elements in raw materials, and the extraction, concentration and separation of valuable metals from mineral products. In the Organic Group, the Purification and Measurement Section continued its work on the separation of $\operatorname{tar}$ constituents, including the purification of pyridine and its homologues, and discovered some new colour reactions for individual bases in this group. A method for the determination of carbazole by nitrosation was developed, and the investigation on the formation of azeotropes between the phenolic and basic constitutions of tar distillates in the creosote oil range has been completed. The report includes a description and diagram of an apparatus in which low-boiling organic compounds can be transferred from part to part by low-temperature distillation and without contact with the atmosphere. An ebulliometer has been designed for use with a thermistor which may be subjected to either the vapour or liquid temperature. Some earlier work on acenaphthylene derivatives has been extended with a Beckmann spectrophotometer, and a Hilger double-beam infrared spectrometer has been brought into use for qualitative and quantitative analysis.

In the first Organic Intermediates Section, besides work on the hydrogenation of pyridine, the hydrogenation of diphenylene oxide has been examined, and the study of co-polymers containing acenaphthylene extended. The second Organic Intermediates Section has prepared further quantities of methyl. chlorosilanes and methylethoxysilanes and obtained some success in attempts to produce silicone grease.
A coating resin containing $1 \cdot 35$ methyl groups per silicon atom was intermediate in performance between two commercial resins as a waterproof coating for high-stability carbon resistors. Besides the work on carbon isotopes already noted, the Section prepared specimens of refined stearic acid, methyl stearate and copper, ferrous, ferric, lead and lithium stearates for the National Physical Laboratory, and developed further an apparatus for the simultaneous preparation and sublimation of aluminium chloride. In the independent High Polymers and Plastics Section, besides the work on the reaction of polyvinyl chloride and on ion-exchange properties stressed by the Board, the investigation of the sorption of water-vapour by phenol-formaldehyde film continued, and considerable progress was made in investigating the interlaminar strength of reinforced plastics.

Appended to the Director's report are lists of publications and patents during the year by members of the Laboratory, a list of staff and members of committees, and of lectures and colloquia in which the Director or staff participated.

\section{FORESTRY IN TRINIDAD AND TOBAGO}

TN the annual report for 1947 (recently published) of the Forestry Department of Trinidad and Tobago*, the conservator, Mr. G. N. Sale, says that the year was in many respects a watershed between the wartime and post-war periods, just as it has proved in other Empire forestry departments. The War has not been without its good aspects in some directions, and forestry and forests are one of them. A marked change of attitude has been noticeable among the local people. They had to buy, though unwillingly, home-grown timber during the War, as there were no timber imports ; they have now become accustomed to it, and local saw-mills are no longer a novelty. An example can be seen in the demand for mora timber, the difficulties of exploitation of which were often complained of in annual reports in the pre-war 'thirties and discussed in reviews in Nature of the period; the demand for this timber, says the report, showed no signs of decreasing, and new areas must be made accessible for the continued supply.

It is curious that it has taken a Second World War to bring about this recognition of the value of its own forests to a country, both to the administration and to the people it governs. The principles of a forest policy formulated in 1942 , the main features of which have so often been repeated throughout the Colonial Empire and outside it, are reiterated in this report. It is to be hoped that this repetition nowadays may no longer go unheeded. The shortage of experienced staff is mentioned and can be appreciated as the stumbling block to progressive advance in almost every branch of work mentioned in the report.

Trinidad and Tobago are not alone here, for there is searcely a Colony of which the forestry staff has been anything near approaching the required strength for the past thirty years. It is this shortsightedness on the part of the authorities concerned which has delayed almost until the twelfth hour so much urgent forestry administration and forest research and settlement.

* Colony of Trinidad and Tobago. Administrative Report of the Conservator of Forests for the Year 1947. Pp. 28. (Trinidad, 1949.) 